\title{
New testament on retroviruses
}

\section{Retroviruses}

edited by John M. Coffin, Stephen H.

Hughes and Harold E. Varmus

Cold Spring Harbor Laboratory Press: 1998.

Pp. 843. $\$ 180$

\section{Robin A. Weiss}

Teaching AIDS on an immunology course recently, I posed the question: how did retroviruses acquire their name? One wit volunteered the answer: "Because they were discovered back in the 1970s." In the HIV era, retroviruses are so pervasive that their replication by reverse transcription appears commonplace, with no sense of the revolution caused by the discovery of reverse transcriptase in 1970. Indeed, it often comes as a surprise to students who have not yet studied virology to learn that other RNA viruses, such as the agents causing influenza or poliomyelitis, do not make DNA. It is the RNA-dependent RNA polymerases that are now regarded as curiosities.

Yet where can one go to bone up on retroviruses? For several years there has been no general text that encompasses up-to-date knowledge of retroviruses. So this is the book we have been waiting for, and no-one should be disappointed.

As the editors state in the preface to Retroviruses, the forerunner was published 15 years ago. But this is not a new edition; rather it is a new testament, written entirely anew and with a different, appropriately modern, structure. The old testament had its genesis 25 years ago when Cold Spring Harbor Laboratory published a textbook called The Molecular Biology of Tumor Viruses. It was superseded in 1980 and 1982 by two separately edited texts on DNA Tumor Viruses and RNA Tumor Viruses which became the bibles of molecular virologists working in or entering the field. The titles betray the focus of effort in those days, for HIV made its debut only in the 1985 paperback edition of RNA Tumor Viruses which had to be expanded to a second volume to include the new discoveries as well as a compendium of retrovirus genome maps. New maps and sequence data are provided in the present book by two excellent appendices with references to $\mathrm{Web}$ sites for international databanks.

Retroviruses begins fittingly with a homage to Howard M. Temin by David Baltimore. There is a scholarly, historical introductory chapter by Peter K. Vogt illustrating the several paradigm shifts that occurred with retroviruses, and citing Thomas Kuhn to justify the volume: "Textbooks are produced in the aftermath of scientific revolutions". This is followed by six synoptic gospels on retroviral organization and replication. A short 'intermezzo' or epistle by the editors on the interactions of retroviruses and their hosts introduces further apostolic chapters on endogenous genomes, vectors, pathogenesis, the apocalypse of HIV, and the revelations of immunological and therapeutic approaches to the control of retroviral infections. The only aspects that are somewhat superficially covered are transmission (other than HIV) and natural immune responses. Although frequently mentioned, the natural history of retroviruses receives less coherent treatment than molecular virology.

Retroviruses will be read in most detail by scientists, although it is a useful volume for physicians and veterinarians, too. This is a serious reference book to be cherished by specialist and novice alike. Its weighty volume (2.5 kilograms) is addressed to the research community rather than to the undergraduate. As the editors state, the chapters are not intended to be read and digested strictly in order, but according to the interest of the reader. Each starts with a concise summary and is handsomely illustrated. Chapters are individually referenced and cover retroviruses in a comparative manner, drawing on common features and principles as well as on the fascinating variety of retroviral pathogenesis. The index, with a

\section{Reproductive thermodynamics}

We may think we know
the answer to the
question 'what is sex?' but
Lynn Margulis and
Dorion Sagan offer a new
philosophical slant on the
subject. Their book What
is Sex? (Simon and
Schuster, $\$ 37.50$ ) views
sex simply as a
consequence of
thermodynamics.
Organisms are open
systems with orifices
through which both
energy and matter can
flow. Photosynthesis
involves flow of gases
through stomata (right)
and, in the same manner,
sex is merely a flow of
matter and dissipation of
energy. Sex exists, they
argue, purely because the
organisms that reproduce
sexually have survived; it
has no inherent
advantage over asexual
reproduction.

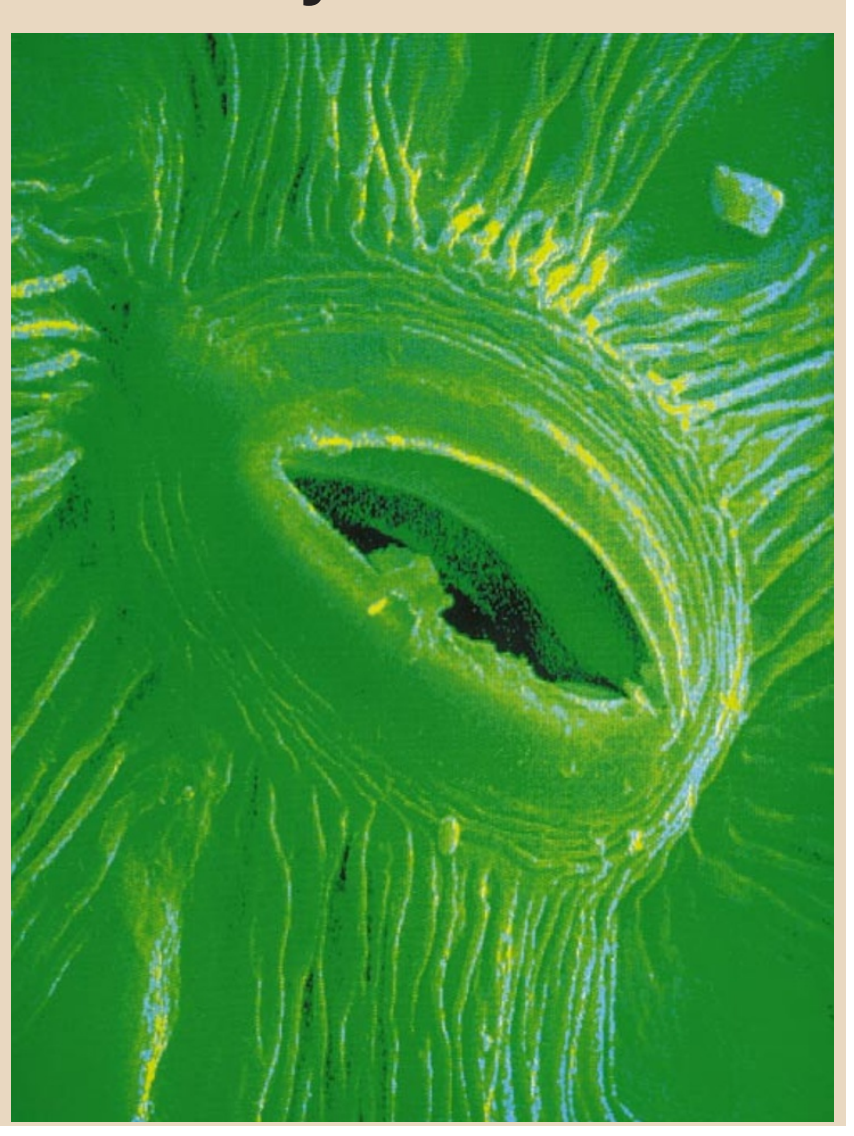

few exceptions (such as HIV neuropathogenesis), provides a genuinely useful homing device to the immense breadth and depth of the subject.

The retrovirologist will continually dip into the volume for reference. Graduate students will now have an easier time writing their theses. The nonviral molecular and cell biologist will find many nuggets of useful information and exposition. My copy disappeared from my office the day it arrived. Better order two copies at once.

Robin A. Weiss is at the Institute of Cancer

Research, Fulham Road, London SW3 6JB, UK.

\section{Connoisseur's collection}

\section{Made to Measure: New Materials for the 21st Century}

by Philip Ball

Princeton University Press: 1998. Pp. 458.

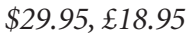

\section{A. Lindsay Greer}

The English are not prominent as wine growers, yet this in no way conflicts with their being able connoisseurs — indeed it 
facilitates an unbiased appreciation of what the world has to offer. In such a manner, Philip Ball — not a materials scientist but an associate editor of Nature - presents a guide to materials for the twenty-first century. The book opens, though, in eighth-century Samarkand with the extraction, from the Chinese, of the secrets of paper-making. Ball points out that, in the post-medieval information revolution, the role of the material paper tends to be underestimated.

Such spicing with historical background is a hallmark of this book. It is refreshing to find a book on 'new' materials that sets them in their context, recognizing that they have a pedigree, and exploiting a description of predecessors to set off the distinguishing features of the new.

The range of materials and applications considered is vast - from artificial blood to artificial legs, light-emitting silicon to holographic memories, photostrictive titanates to microporous clays, hydrogels for drug delivery to designed bacterial polymers, fuel cells to artificial diamonds. Occasionally, Ball may stray too far - few would treat gene therapy within the range of new materials.

Omissions are mostly intended. Hightemperature superconductors are avoided for the good reasons that they have had extensive publicity already and are now the subject, not of breakthroughs but of hard grind to make their use practicable. Ball is aware that new, expensive materials are destined for specialized uses; justifiably, he chooses not to focus on structural materials. All the same, within his theme of materials 'made to measure', it is a shame not to recount the story of modern steels designed in the virtual mill of the computer. The coverage, strong on history, is also well up to date. It is good to find, for example, a thorough treatment of the new blue lightemitting diodes.

The book is far from being just a list of diverse materials. It also offers analysis of trends. Ball's picking out of themes in biomimetics, for example, is masterly. In this way the book should have much more than ephemeral interest. Ball is ready to acknowledge the wider factors influencing the adoption or rejection of a new material — industrial realities, wider economics, ecological concerns. Many books on new materials have more hyperbole than substance; this is not one of them. Ball writes of his materials with enthusiasm, but tempered by realism. He recognizes that most (but far from all) new materials will be passing wonders.

For a book on this subject, it is ironic that its material presentation - paper, binding, printing, illustrations - is old-fashioned. This may make it less immediately attractive to buy than its accessible writing deserves. The background science (band structure of semiconductors, architecture of cells) necessary to appreciate the main message is

\section{Mathematics of the natural world}
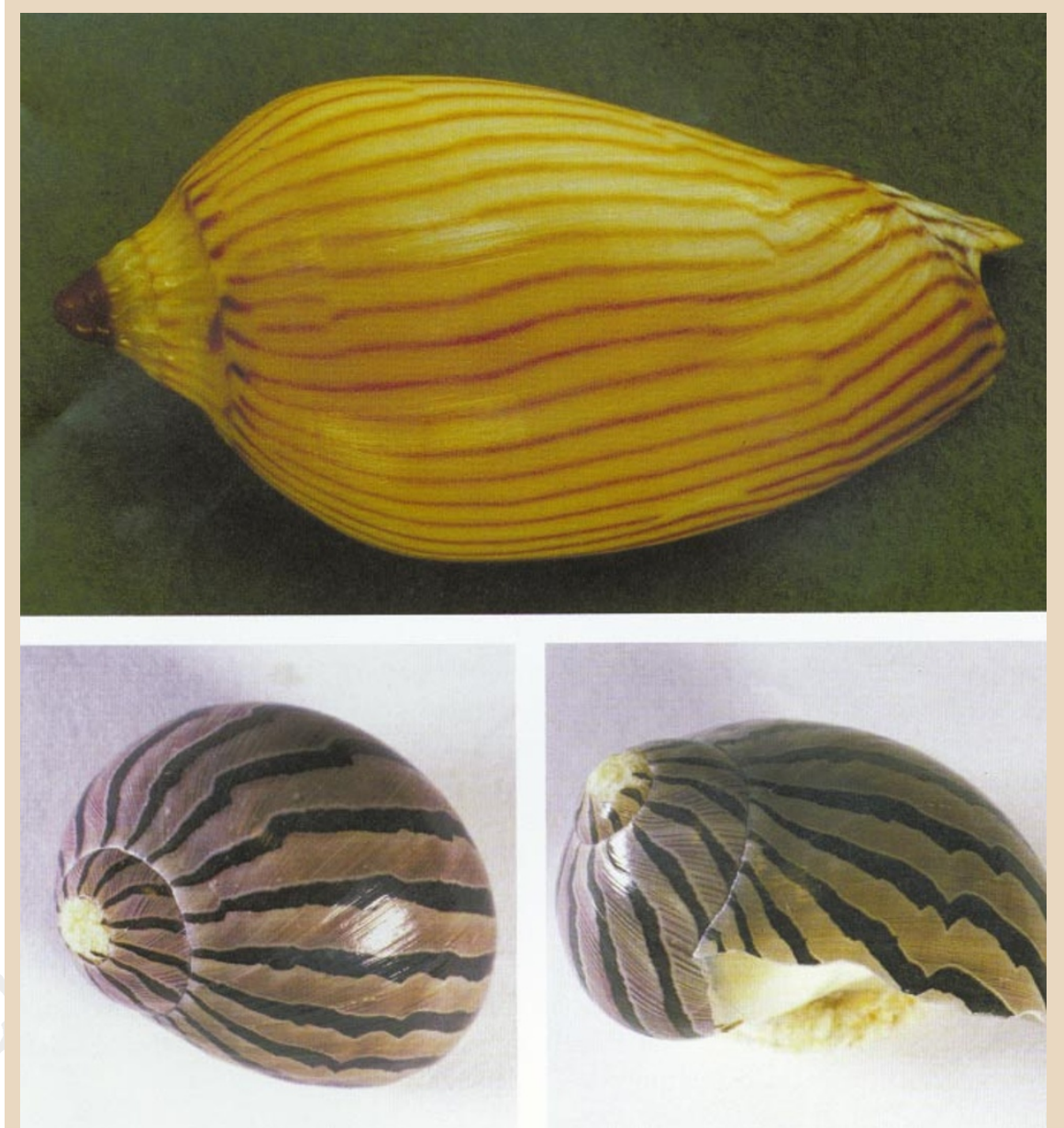

As Philip Ball explains in Made to Measure, reviewed left, mollusc shells not only are sophisticated composite materials but can be ornately decorated with coloured pigments produced by cells in the proten outer mantle. The patterns are frozen 'chemical waves' generated by complex, nonlinear interactions between cells during shell growth, which modulate the production of pigment. The images here are taken from the enlarged version of Hans Meinhardt's The Algorithmic Beauty of Sea Shells (Springer, DM89, \$54.95, £34), the first edition of which was reviewed in Nature 375, 745 (1995).

described with a fluency and accuracy that puts most practising scientists to shame.

Inevitably there are small errors. Some may be distressed by Ball's sometimes uncertain distinction between strength and stiffness, others by his description of the Mancunian James Joule as a Scot. Yet the treatment overall is authoritative, and is supported by a good bibliography.

There are some 160 references to individuals or institutions involved with current developments. Of these, $61 \%$ are from the United States, 11\% from the United Kingdom (equal to all of continental Europe combined), and 10\% from Japan. Does this reflect the true distribution of progress, or rather national variations in countries' ability and willingness to promote their wares? Whatever the answer, Ball's selected case of materials is worth having.

A. Lindsay Greer is in the Department of Materials Science and Metallurgy, University of Cambridge, Pembroke Street, Cambridge CB2 3QZ, UK.

\section{When language doesn't add up}

\section{Twice As Less: Black English and the Performance of Black Students in Mathematics and Science \\ by Eleanor Wilson Orr}

Norton: 1997. Pp. 242. \$12.95, £9.95 (pbk)

\section{Geoffrey K.Pullum}

In 1972, Washington DC's Board of Education drew lots to pick 41 students from the city's public schools for free enrolment at the private, coeducational Hawthorne School. Nearly all were native speakers of African American Vernacular English (AAVE). The teachers were at first baffled by the new students' curious though systematic conceptual errors in mathematics, but ultimately developed strategies that improved results dramatically. 